\title{
UMA CRÍTICA ÀS TEORIAS CLÁSSICAS DA APRENDIZAGEM E À SUA EXPRESSÃO NO CAMPO EDUCATIVO
}

\author{
A CRITICAL ARGUMENT ON CLASSICAL LEARNING THEORIES AND \\ ON THE WAY THEY ARE EXPRESSED IN EDUCATIONAL PRACTICES \\ UNE CRITIQUE AUX THÉORIES CLASSIQUES D’APPRENTISSAGE \\ ET LEUR EXPRESSION DANS LE CHAMPS ÉDUCATIF \\ UNA CRÍTICA A LAS TEORÍAS CLÁSICAS DEL APRENDIZAJE \\ Y A SU EXPRESIÓN EN EL CAMPO EDUCATIVO
}

\author{
Elizabeth Tunes * \\ Maria Carmen Villela Rosa Tacca ** \\ Albertina Mitjáns Martínez ***
}

\section{RESUMO}

Neste trabalho, tem-se o intuito de buscar compreender modos de interpenetração da psicologia $e$ da educação. A reflexão é tecida tomando-se as teorias da aprendizagem como o cenário de um ciclo de produção teórica da psicologia, buscando-se fios das meadas em modos concretos com que professores e estudantes afirmam suas práticas no campo da educação. Tendo como fundamento a perspectiva histórico-cultural da psicologia, é feito um exame critico das teorias de aprendizagem mais conhecidas, procurando-se demonstrar seus pontos de convergência e seus limites para tratar da diversidade das formas de aprendizagem humanas, especialmente as que acontecem no âmbito da instituição escolar.

Palavras-chave: Psicologia. Educação. Teorias da aprendizagem.

* Doutora em Psicologia pela Universidade de São Paulo (1981). Professora da Faculdade de Educação da Universidade de Brasília (bethtunes@globo.com).

** Doutora em Psicologia pela Universidade de Brasília (2000). Professora da Faculdade de Educação da Universidade de Brasília (mctacca@yahoo.com.br).

*** Doutora em Ciências Psicológicas pela Universidad de Habana (1993). Professora da Faculdade de Educação da Universidade de Brasília (amitjans@terra.com.br). 
É inegável a forte articulação que há entre psicologia e educação e entre psicologia e pedagogia. Reciprocamente, nutrem-se de forma vigorosa. Embora no passado anterior à sua instituição como ciência a psicologia defendesse para si um projeto que a separava claramente da vida vivida, dedicando-se a ficções e abstrações, conforme o exame de Vigotski (2003), historicamente, com a emergência da escola, ela ganha um forte impulso que lhe permite trilhar em várias direções na busca da realização de seu projeto científico (ver, por exemplo, POSTMAN, 1999; BRITO, 2005). É tal a força dessa articulação que não há um, entre os grandes teóricos da psicologia, que não tenha tematizado a educação e a pedagogia e, entre os da educação, aquele que não tenha adentrado o campo da psicologia em seus estudos. Não haveria como ser de outro modo. Afinal, se à psicologia interessa o estudo do comportamento social do homem, como quer Vigotski (1996) e, na sociedade moderna, a educação vem sendo, historicamente, valorizada de um modo vertiginosamente crescente, a expectativa é que essas áreas sejam, cada vez mais, interpenetrantes. Alguns ciclos de produção teórica da psicologia prestam-se com muita clareza como ilustração dessas influências mútuas.

A emergência da psicologia do desenvolvimento, por exemplo, é um correlato histórico importante do surgimento da escola moderna. (ARIĖS, 1981; BOTO, 2002; POSTMAN, 1999). Seu apogeu, contudo, é, de certo modo, adiado no tempo, talvez devido à pobreza presumida de seu estatuto científico (ver TUNES, 2002; TUNES; BARTHOLO JÚNIOR, 2004), atropelado que foi pelo apogeu do ciclo das teorias da aprendizagem com um estatuto científico presumidamente mais vigoroso. Esses ciclos, por sua vez, como ondas - para usar a mesma metáfora de Toffler (1980) - interpenetram-se, sobrepóem-se e deixam marcas notáveis na vida social do homem, que inclui, indubitavelmente, as práticas sociais de educação.

Neste trabalho, tem-se o intuito de buscar compreender um pouco os modos de interpenetração da psicologia e da educação. Nesta primeira iniciativa, a reflexão é tecida tomando-se as teorias da aprendizagem como o cenário de um ciclo de produção teórica da psicologia e buscando-se fios das meadas em modos concretos com que professores e estudantes afirmam suas práticas no campo da educação. Não se pretende esgotar o tema, mas apenas resgatar um pouco do legado do nosso passado recente.

Historicamente, o estudo científico da aprendizagem toma fôlego ao final do século XIX, sendo prontamente acolhido pelos educadores. Perdura até os dias de hoje, embora com intensidade e desdobramentos mais fracos no campo da educação. Desde aquela data, houve enorme expansão da pesquisa psicológica sobre a aprendizagem, acompanhando-se de uma produção teórica abundante e bastante diversa. O exame dessa diversidade é o ponto de partida da reflexão que se pretende fazer. 


\section{SOBRE A DIVERSIDADE DE TEORIAS DA APRENDIZAGEM}

Desde que emergiu como ciência, o que aconteceu ao final do século XIX, a psicologia tem se dedicado a compreender o fenômeno da aprendizagem, procurando responder a questôes como o que é aprendizagem e como os organismos aprendem. $\mathrm{Na}$ tentativa de elucidar essas questôes, os estudiosos da psicologia construíram diversas teorias que, apesar de guardarem semelhanças entre si, também mostravam muitas diferenças e até mesmo alguns antagonismos. Mas, se essas teorias tratavam do mesmo fenômeno - aprendizagem -, como entender a existência de tantas diferenças e antagonismos?

Ernest Hilgard, professor de psicologia da Universidade de Stanford, escreve, em 1956, um livro interessante sobre teorias de aprendizagem (HILGARD, 1966), considerado, hoje, um clássico. Ele procura apresentar, de modo abrangente, sintético e crítico, algumas das teorias de aprendizagem mais importantes, elaboradas na primeira metade do século XX. Examina, detidamente, sete sistemas teóricos (os de Thorndike, de Guthrie, Skinner, Hull, Tolman, de Lewin e dos psicólogos da Gestalt), além dos desdobramentos e implicações de outros sistemas teóricos (como o de Freud e o dos modelos matemáticos) para a compreensão do fenômeno da aprendizagem. Admite a existência de controvérsias entre as teorias de aprendizagem, atribuindo-a a divergências no fato focalizado para estudo e na sua interpretação. Sobre essa questão, diz o seguinte:

As preferências do teórico o levam geralmente a se concentrar num tipo de situação de aprendizagem (grifo nosso), negligenciando outros. Sua teoria é então apropriada a essa situação, mas se torna um tanto deficiente em relação a outros problemas de aprendizagem (HILGARD, 1966, p. 8).

Para o exame geral das controvérsias, ele agrupa as teorias em duas famílias, a que chamou de teorias do estímulo-resposta e teorias cognitivas, reconhecendo, todavia, que esses dois grupos não são internamente homogêneos e que ambos não abarcam a totalidade das teorias de aprendizagem existentes. Na verdade, o agrupamento é apenas uma estratégia para ilustrar as principais controvérsias que reconhece existir entre as teorias. No caso dessas duas famílias, as divergências residiriam no fato em si da aprendizagem, nos seus mecanismos e na sua repercussão ou desdobramentos.

No que diz respeito ao fato da aprendizagem, isto é, na resposta à questão "o que é aprendido?”, os teóricos do grupo estímulo-resposta diriam que são hábitos, e os cognitivistas, estruturas cognitivas. Em decorrência dessa divergência quanto ao que é aprendido, aparecem, logicamente, as controvérsias quanto aos mecanismos da aprendizagem. Para os teóricos do primeiro grupo, eles seriam mecanismos periféricos, e para os outros, centrais. Esclarecendo melhor, com as palavras de Hilgard (1966):

Os teóricos do estímulo-resposta tendem a acreditar que um tipo de resposta muscular encadeada, ligada talvez por respostas antecipatórias fracionárias ao objetivo, serve para manter um rato correndo até uma caixa-alimento distante. O teórico cognitivo, por outro lado, 
infere mais livremente processos cerebrais centrais tais como memórias ou expectativas, como integradores do comportamento que procura o objetivo (p. 12).

Finalmente, a terceira controvérsia importante residiria na repercussão ou desdobramentos da aprendizagem, ou seja, na resposta à questão: tendo aprendido e, diante de um problema novo, como o aprendiz chega à solução? O teórico da família estímuloresposta privilegiaria a idéia de que a aprendizagem cria história ou um arcabouço de experiência do qual o aprendiz lança mão, diante de uma nova situação. $\mathrm{O}$ cognitivista afirmaria que o mais importante é que a aprendizagem cria a possibilidade de insight. Nas palavras de Hilgard (1966):

O psicólogo do estímulo-resposta prefere olhar para a história passada daquele que aprende para encontrar as fontes de solução, enquanto o psicólogo cognitivo, de preferência, olha para a estrutura contemporânea do problema. Sua preferência pelo passado não exige do psicólogo do estímulo-resposta que ignore a estrutura presente do problema nem a preferência pelo presente exige do psicólogo cognitivo que ignore o passado. Não se deve deduzir, devido a essa diferença de preferência, que qualquer um dos teóricos esteja cego em relação à totalidade da situação de aprendizagem (p. 14).

Vê-se, assim, que uma dentre as possibilidades para compreender a abundância de teorias da aprendizagem que marcou fortemente a história da psicologia, na primeira metade do século XX, deixando seus reflexos até os dias de hoje, encontra-se na idéia de que, talvez, as teorias se referissem, cada uma, a diferentes formas ou tipos de aprendizagem. Mas isso ainda não é tudo, pois, se assim fosse, bastaria criar um super-sistema teórico, agregando as diversas teorias nas suas referências tipológicas específicas, e estaríamos diante de um quadro compreensivo do que viria a ser a aprendizagem. Um primeiro passo nessa direção, talvez, seja, então, encontrar o ponto em torno do qual os diversos teóricos concordavam entre si e dele partir para a elaboração de um super-sistema teórico.

A análise de Hilgard (1966) ajuda nessa identificação. Para ele, é muito difícil chegar a uma definição inteiramente satisfatória do que venha a ser aprendizagem. Apesar disso, ele ensaia uma proposta, admitindo, contudo, que ela contém muitos termos indefinidos:

Aprendizagem é o processo pelo qual uma atividade tem origem ou é modificada pela reação a uma situação encontrada, desde que as características da mudança de atividade não possam ser explicadas por tendências inatas de respostas, maturação ou estados temporários do organismo (por exemplo, fadiga, drogas etc.) (p. 3).

Não cabe, aqui, tratar do modo como ele define e distingue tendências inatas de respostas, maturação ou estados temporários do organismo. Vale, contudo, destacar que a definição que apresenta nada acrescenta à compreensão do que venha a ser aprendizagem, por defini-la como um resultado de tudo aquilo que não é aquilo outro. Mas, o 
importante a ressaltar é que, a despeito de não ser possível formular uma definição satisfatória do que venha a ser aprendizagem, segundo o autor, "a definição não é a fonte principal de desacordo entre as teorias" (p. 7); a "controvérsia recai sobre o fato e a interpretação, e não sobre a definição" (p. 8) do fenômeno da aprendizagem. Ou seja, ainda que admitindo a precariedade e a provisoriedade de qualquer definição, todos os teóricos concordam, tacitamente, que é possível uma formulação genérica sobre o que seja aprendizagem, e cada um deles propõe a sua, não como uma teoria específica sobre um tipo particular de aprendizagem, mas como a teoria da aprendizagem. Ou seja, cada um parte do pressuposto de que está tratando de todo e qualquer tipo de aprendizagem e que sua teoria pode dar conta dessa totalidade.

\section{SOBRE A ORIGEM DA CONTROVÉRSIA ENTRE AS TEORIAS DA APRENDIZAGEM}

Fred S. Keller (1970), um importante estudioso da psicologia, dedicado à compreensão da aprendizagem, especialmente, no âmbito de uma teoria conhecida como Teoria do Reforço, apresenta-nos uma reflexão interessante, num livro introdutório, escrito em 1954. Ele começa chamando a atenção do leitor para a diversidade de situações em que empregamos o verbo aprender. Admitimos a idéia de que aprendemos desde que nascemos. Aprendemos a engatinhar, a andar, a falar, a distinguir uma voz de outra, a não colocar o dedo na tomada; aprendemos a andar de bicicleta, a dirigir um automóvel, a nadar, a contar a verdade e a ficar envergonhados quando fazemos algo errado, a ler, a fazer operaçōes aritméticas básicas, a resolver equações matemáticas envolvendo integrais e derivadas, a interpretar um texto, a recitar poesias, a manusear o dinheiro, fazer compras; aprendemos a prever o tempo, a criar animais, a curar doenças, a usar o computador; aprendemos também a ensinar. A lista do que dizemos que aprendemos no curso de nossa vida pessoal é interminável e há mesmo quem diga que aprendemos a amar, a viver e até que aprendemos a aprender.

Keller convida-nos à reflexão, propondo as seguintes questôes: serão iguais todas essas aprendizagens? $\mathrm{O}$ aprender a andar de bicicleta será igual ao aprender a falar? Esta última aprendizagem será igual ao aprender a resolver equações matemáticas envolvendo integrais e derivadas, e este, por sua vez, é um processo semelhante ao da aprendizagem de curar doenças e ao do aprender a ensinar? Aceitando o convite de Keller, podemos continuar a nossa reflexão: será que tudo por que passamos em nossa vida é fruto de aprendizagem? Será que podemos mesmo dizer que aprendemos a amar, a viver e que aprendemos a aprender? Admitindo, ainda que provisoriamente, que se responda afirmativamente a todas essas questôes, cabe ainda perguntar: será que todas as aprendizagens de todos os seres vivos podem ser descritas e compreendidas cientificamente por meio de uma lei universal da aprendizagem, à semelhança da lei da gravitação universal de Newton, na Física? E ainda, mesmo que a resposta a esta pergunta seja sim, por onde devemos começar: pela busca da lei universal para se atingir, em seguida, a particularização, 
ou pela descrição, análise e compreensão de cada tipo particular de aprendizagem para, então, poder atingir a lei universal?

A nossa idéia, aqui, é que os estudiosos da psicologia do final do século XIX e primeira metade do século XX, época em que foram formuladas as principais e as mais importantes teorias da aprendizagem, começaram, efetivamente, pelo conhecimento dos tipos particulares de aprendizagem, todavia com a pretensão de estarem tratando da totalidade do fenômeno aprendizagem nos seres vivos. A abundância de teorias pode, assim, ser explicada pela multiplicidade dos tipos de aprendizagem a que dizem respeito. Mas é a pretensão de cada teórico, ao procurar estender os fatos, que desvendou toda e qualquer forma de aprendizagem dos seres vivos uma das fontes que, talvez, faça emergir as principais diferenças e os antagonismos entre as diversas teorias.

\section{O VIÉS REDUCIONISTA DAS TEORIAS DA APRENDIZAGEM}

Examinada cada teoria de aprendizagem na especificidade do tipo a que se refere, delimitando-se, assim, o seu campo de vigência, é possível extrair de cada uma informaçôes importantes e conceitos elucidativos para a análise psicológica do fenômeno da aprendizagem. Essa iniciativa, contudo, vale afirmar, não é original, nem recente.

Vigotski (1996), por exemplo, procura demonstrar que os processos do reflexo condicional, desvendados por Pavlov e outros reflexologistas russos, podem ser teoricamente instituídos como a base material biopsicológica para a edificação de novas formas de comportamento, tipicamente humanas, especialmente aquelas que apresentam a propriedade da consciência (ver TUNES; BARTHOLO JÚNIOR, 2004). Todavia, apresenta críticas aos trabalhos de Pavlov e à reflexologia russa, de um modo geral, não com o intuito de invalidar a teoria dos reflexos condicionais nos seus postulados e conceitos básicos, mas com a intenção de apontar para a necessidade de delimitação de seu campo de vigência, dada a pretensão pavloviana de tomá-la como a lei universal da aprendizagem:

A reflexologia clássica mantém-se em suas investigações dentro de um princípio científico universal darwiniano, reduzindo tudo ao mesmo denominador comum. E, precisamente por ser excessivamente geral e universal, esse princípio não oferece à ciência um meio direto para julgar suas formas particulares e individuais. No fim das contas, também resulta impossível para a ciência concreta do comportamento humano limitar-se a ele, assim como uma física concreta não pode se limitar ao princípio da gravidade universal. São necessárias balanças, aparelhos e métodos especiais para conhecer o mundo terreno concreto, material, limitado, sobre a base de um princípio geral. O mesmo ocorre com a reflexologia. Tudo leva a ciência do comportamento do homem a sair dos limites do experimento clássico e procurar outros meios de conhecimento (p. 4).

Skinner também procede de um modo similar a Vigotski, em relação à teoria do reflexo condicional. Em seu primeiro livro - The Behavior of Organisms (1938) - ele admite os postulados e conceitos pavlovianos básicos, delimitando, contudo, o seu 
campo de validade, ao afirmar que vigem apenas para um tipo particular de aprendizagem ou, em outros termos, dizem respeito a somente uma forma de condicionamento. É a partir desta delimitação que justifica a sua nova formulação acerca do condicionamento operante. Entretanto, assim como Pavlov, deixa-se capturar pela armadilha do reducionismo, ao pretender que as leis reguladoras do comportamento operante fossem válidas para o restante da totalidade que não dissesse respeito a reflexos condicionais e incondicionais. Para ele, o condicionamento operante seria o princípio explicador de ações as mais distintas, desde a mera manutenção do equilíbrio, o andar, até $o$ ato de escrever.

A posição de Skinner (1972) merece, aqui, um destaque, por apresentar peculiaridades que interessam à nossa argumentação. Em primeiro lugar, ele define aprendizagem como "uma mudança na probabilidade da resposta" (p. 78), em função (no sentido matemático do termo) da variação na probabilidade do reforçamento. Nessa definição, ele pretende e evita termos que considera inadequados para a compreensão da aprendizagem. No seu texto Are theories of learning necessary?, faz severas críticas às teorias de aprendizagem, argumentando que são inadequadas e, portanto, desnecessárias para compreensão do fenômeno. Agrupa-as em três tipos. Um deles, próprio do campo da psicologia fisiológica, interessa-se pelas ligações sinápticas que são formadas ou desfeitas, pela reorganização ou desorganização de campos elétricos ou acontecimentos congêneres, quando um organismo aprende. Outro, muito assemelhado ao primeiro, faz referência a eventos mentais que explicariam a ocorrência da aprendizagem quando se diz, por exemplo, que um organismo aprende porque "encontra prazer" ou porque "tem a expectativa de que algo aconteça" (p. 70). Finalmente, o terceiro tipo de teorias se agruparia em torno do que o autor denomina de Sistema Nervoso Conceitual - uma espécie de homúnculo da mente -, que é tomado não como uma estrutura subjacente às mudanças fisiológicas e bioquímicas, mas como um sistema dinâmico que produz determinados resultados. Seriam, usando as palavras do autor, respectivamente, as teorias neurais, mentais ou conceituais da aprendizagem.

A crítica importante que decorre do exame de Skinner a essas teorias é o seu caráter tautológico: toma-se como explicação da aprendizagem aquilo que deveria ser explicado. Daí, a sua desnecessidade. O que propõe, em seu lugar, seria um programa de pesquisa que, ao contrário de se orientar para testar teorias, se voltasse para a construção de uma teoria, conforme diz:

Isso não exclui a possibilidade de teoria, num outro sentido. Para além da coleção de relações uniformes, encontra-se a necessidade de uma representação formal de dados que possam ser reduzidos a um número mínimo de termos. Uma construção teórica pode possibilitar maior generalidade do que uma assembléia de fatos (SKINNER, 1972, p. 100).

É, entretanto, nessa busca que, a nosso ver, Skinner cai na armadilha do reducionismo. $\mathrm{Na}$ tentativa de evitar os termos neurais, mentais e conceituais, passa a tratar todo e qualquer tipo de aprendizagem como sendo uma coisa só: tudo se resumiria à mudança na 
probabilidade de resposta, função de variação na probabilidade de reforçamento. É como se ele desrespeitasse a própria regra que valoriza: teorizar antes da hora.

À parte as críticas que possam ser dirigidas à posição epistemológica de Skinner a respeito do que venha a ser uma ciência da psicologia ou uma teoria científica - o que não cabe, aqui, examinar -, o importante a salientar, conforme ele o fez, é o caráter tautológico dos principais conceitos das principais teorias psicológicas de aprendizagem, de um lado, e, de outro, a sua forte marca reducionista. Por que isso aconteceu?

A nossa suposição é de que, na base desse acontecimento na história da psicologia, encontra-se uma busca fortemente inspirada na visão naturalista hegemônica, aliada à formulação de uma pergunta feita em bases equivocadas. A pergunta que os estudiosos faziam era Como ou por que os organismos aprendem, assumindo-se a premissa de que haveria uma forma única, padronizada, e que seria o princípio régio universal que explicaria a aprendizagem dos organismos. A questão que apresentamos é: será que para o fenômeno a que chamamos de aprendizagem cabe pretender a formulação de um princípio único, de caráter universal e, portanto, totalizante que o explicaria? A premissa adotada é outra: a aprendizagem é um fenômeno diverso. Sendo este o caso, ao estudioso e ao teórico da aprendizagem, ao invés da busca pelo princípio único e universal que a explicaria, não caberia, exatamente o contrário? Isto é, as tentativas deveriam caminhar não na direção daquilo que mostra a uniformização do fenômeno, mas sim do que permita compreender o que rege a sua diversidade.

No caso da aprendizagem humana, considerada pela grande maioria dos teóricos como localizada no topo de uma hierarquia de complexidade, a questão formulada torna-se plena de sentido. Pode-se admitir que esta não seja meramente a forma mais complexa (uma questão de quantidade), mas uma outra forma de manifestação da diversidade. Por que haveria, então, tantas formas diversas de aprender? Não seria essa a questão a responder?

Não há novidade absoluta nessa questão. Vigotski (1997) já a formulara em seus Fundamentos de Defectologia, ao falar do desenvolvimento cultural do homem e, uma vez que estabelece uma clara relação entre desenvolvimento e aprendizagem, ao afirmar a diversidade das formas de desenvolvimento, admite, como premissa, o fato da diversidade na aprendizagem. Para ele, assim, a aprendizagem humana é um fenômeno cultural, historicamente condicionado pelas condiçôes concretas de vida e, por isso mesmo, com enorme amplitude de variação em suas formas de manifestação. Caberia, pois, ao estudioso desvendar o porquê de tal diversificação. Nesse sentido, suas preocupações estariam, a nosso ver, muito mais próximas de $A$ Origem das Espécies, de Darwin, do que de $O$ Capital, de Marx, já que o primeiro preocupava-se em compreender o leito variante da história das espécies e, o segundo, os aspectos determinadores da história.

Aprendemos muitas coisas no curso de nossas vidas. Algumas dessas aprendizagens decorrem da nossa relação direta com os objetos e com os acontecimentos de que participamos; outras decorrem da intenção de um Outro ser que, efetivamente, se propõe a nos ensinar. Isso já não é uma grande diferença no ponto de partida. 


\section{APRENDIZAGEM ESCOLAR: DIVERSIDADE E COMPLEXIDADE}

$\mathrm{Na}$ instituição escolar são produzidos diferentes tipos de aprendizagem. No entanto, é freqüente encontrar a expressão aprendizagem escolar sendo utilizada para caracterizar, de forma global, a aprendizagem que se dá na escola, como se essa fosse de tipo único ou homogênea. Realmente, no locus constituído pela instituição escolar, encontramos os mais diversos tipos de aprendizagem, tanto se consideramos o fato em si, quanto os mecanismos ou sua repercussão e desdobramentos, se formos utilizar as conceituações de Hilgard (1956). Também tomando, por exemplo, a classificação de resultados de aprendizagem utilizada por Pozo (2000), podemos reconhecer que na escola também se dão aprendizagens de fatos e condutas, aprendizagem social, aprendizagem verbal e conceitual, e aprendizagem de procedimentos, ou seja, muitas e diversas formas de aprendizagem.

No entanto, o interesse, aqui, é focalizar a aprendizagem que é própria da instituição escolar, na sua condição de instituição constituída para a transmissão da cultura elaborada pela humanidade. Em essência, o interesse concentra-se sobre aquela aprendizagem "orientada a dominar os modos generalizados de ação na esfera dos conceitos científicos" (MARKOVA; ABRAMOVA, 1986, p. 105). Esse sistema de conceitos científicos constitui, de fato, os aspectos medulares dos currículos escolares e das disciplinas que o integram. Assim, a seguir será utilizada a expressão aprendizagem escolar com esse sentido específico.

Apesar da falta de reconhecimento das diferenças e da forte tendência homogeneizadora que caracterizam ainda os processos educativos, a diversidade da aprendizagem escolar constitui um fato inquestionável que pode ser compreendido, entre outros fatores, pela complexidade de sua própria natureza constitutiva. $\mathrm{O}$ caráter simultaneamente social e individual da aprendizagem escolar constitui, no nosso modo de ver, uma das razões pelas quais se torna difícil que uma única teoria da aprendizagem, ou uma única teoria integradora, possa dar conta da diversidade e complexidade desse tipo de aprendizagem.

A perspectiva histórico-cultural de desenvolvimento humano tem salientado a dimensão social da aprendizagem escolar, dimensão pouco considerada em outros enfoques teóricos da aprendizagem. O reconhecimento do caráter histórico e cultural da constituição da psique humana e, especialmente, o papel essencial que é conferido ao Outro nos processos de aprendizagem e desenvolvimento na ontogênese remetem à compreensão da aprendizagem escolar não apenas como um processo do sujeito individual, mas como um processo de natureza social.

O caráter social da aprendizagem escolar expressa-se de múltiplas formas. Uma delas, por exemplo, tem relação com a natureza dos conteúdos e habilidades que devem ser aprendidos. Esses conteúdos (expressos em conceitos e sistemas de conceitos) e habilidades (procedimentos de ação em relação aos conteúdos) têm sido socialmente constituídos e representam produtos culturais diversos, cuja própria natureza participa na orientação das ações do aprendiz, contribuindo para a sua diversidade. 
Outra forma em que se expressa a natureza social do processo de aprendizagem é na posição que ocupa o aprendiz no processo de ensino-aprendizagem, processo que é essencialmente social, relacional. $\mathrm{Na}$ aprendizagem, são assumidos "papéis sociais" fortemente influenciados por inúmeros fatores, entre eles as representações sociais dominantes sobre o aprender e as exigências colocadas na relação pedagógica. Nessa direção, Itelson (1986) afirma:

Em princípio, a aprendizagem depende da posição que ocupa o educando no campo de forças e influências pedagógicas, isto é, da função que este realiza na situação pedagógica. Esta função pode ser:

a) percepção passiva e assimilação da informação que se oferece desde fora;

b) busca independente ativa, descobrimento e utilização da informação;

c) busca organizada dirigida desde fora, descobrimento e utilização da informação (p. 97).

O caráter social da aprendizagem escolar expressa-se também no papel do Outro nesse processo, um Outro que intencionalmente se propõe, como já mencionado, a ensinar. O conceito de zona de desenvolvimento proximal de Vigotski ilustra a concepção de que os processos de desenvolvimento e aprendizagem humanos são essencialmente sociais. O Outro, pelas suas ações e formas de comunicação em que estas ações se inserem, constitui um importante elemento na definição das características do processo de aprendizagem. Os tipos de tarefas que se pede ao aluno para desenvolver, as características das relaçóes professor-aluno, a emocionalidade que caracteriza o espaço relacional e as expectativas geradas na relação pedagógica são alguns exemplos dos muitos temas que têm sido objeto de pesquisa nesse campo e que mostram, com clareza, o caráter social da aprendizagem escolar.

A natureza diversa dos conteúdos e habilidades a serem aprendidas, as posiçóes diferenciadas que o aprendiz ocupa na situação pedagógica e as múltiplas e diferenciadas nuances da relação com o Outro no processo de ensino-aprendizagem, referidas anteriormente, constituem apenas alguns elementos que contribuem para explicar a complexidade constitutiva da aprendizagem escolar, dificilmente passível de ser apreendida por teorias únicas e unificadoras.

Ao anterior soma-se a diversidade dos processos psíquicos envolvidos no processo de aprender e sua expressão nas diferentes ações e operações específicas constitutivas desse processo. Para alguns autores (TIJOMIROV, 1984; ITELSON, 1986; DAVIDOV; MARKOVA, 1987, entre outros), exemplos dessas ações são: imitação, percepção literal ou semântica, repetição, treinamento, exercitação segundo modelos e regras elaborados, eleição de perguntas e problemas, busca de informaçōes e princípios gerais, julgamento, compreensão, criação, solução de problemas, avaliação dos resultados, ensaio e erro, experimentação, eleição e aplicação de princípios gerais e conceitos, entre outras. Sejam estas ou outras as operações consideradas como constitutivas da aprendizagem escolar, a questão que se quer salientar é que esse tipo de aprendizagem implica operações ou ações muito diversas, que dependerão tanto do objeto do conhecimento e das características da relação 
pedagógica, quanto dos níveis de desenvolvimento e características do próprio aprendiz.

Processos psíquicos diversos como atenção, percepção, pensamento, imaginação, motivação e outros articulam-se de formas diversas na aprendizagem escolar, desafiando os cientistas na busca de conceituaçóes que contribuam cada vez mais para uma representação complexa desse processo.

Fazendo uma análise do desenvolvimento dos conceitos científicos na infância, Vigotski (1968) já afirmava:

O desenvolvimento dos conceitos, ou do significado das palavras pressupóe, por sua vez, a evolução de muitas funções intelectuais: a atenção deliberada, a memória lógica, a abstração, a habilidade para comparar e diferenciar. Esses processos psicológicos complexos não podem ser dominados por meio da aprendizagem isolada (1968, p. 99).

Nessa reflexão, Vigotski apontava a complexidade constitutiva do desenvolvimento dos conceitos científicos, processo para o qual considerava o ensino um elemento essencial.

No desenvolvimento da perspectiva histórico-cultural, uma importante linha de trabalho tem sido aquela direcionada à compreensão da integridade na qual o psíquico aparece na tentativa de quebrar com formas fragmentadas e parciais na compreensão do funcionamento psicológico humano. As categorias sujeito e personalidade, mesmo com diferentes definições teóricas, têm sido utilizadas com este objetivo (VIGOTSKI, 1997; ABULJÁNOVA, 1985; BOZHOVITCH, 1985; GONZÁLEZ REY, 1997, 2002, entre outros).

No caso específico da aprendizagem, tem-se reconhecido, cada vez com maior nível de complexidade nas conceituaçóes teóricas, as formas articuladas e integradas com que outros processos ou formaçôes psicológicas se expressam no processo de aprender. Por exemplo, Pranguisshvili (1975/1986), influenciado pelas posições de Uznadze, afirmava:

Se não se parte do conhecimento do estado inicial íntegro do sujeito da atividade, isto é, da disposição, não é possível descrever, modificar, nem explicar os processos de vivências e açôes que têm lugar durante a realização da atividade de aprendizagem (p. 119).

Mesmo discordando da forma mecânica como é apresentada a determinação da aprendizagem por parte da personalidade, reconhece-se aqui a importância dada, para a compreensão da aprendizagem, a categorias como sujeito e personalidade, que, na perspectiva aqui adotada, apontam com força para a complexidade constitutiva desse processo.

No desenvolvimento atual de uma Teoria da Subjetividade numa perspectiva histórico-cultural (GONZÁLEZ REY, 1997; 2002; 2003), a aprendizagem é compreendida como um processo da subjetividade na sua simultânea condição de subjetividade individual e subjetividade social, destacando-se a importância da categoria sentido para sua compreensão. 
González Rey afirma:

Considerar o pensamento uma função de sentido nos conduz a considerar a aprendizagem também como um processo de sentido, o qual implica considerar o sujeito que aprende na rota singular de sua aprendizagem através dos afetos produzidos nesse processo, os que não estão microlocalizados na sala de aula. Através da categoria sentido, que aparece como uma produção subjetiva, integram-se em cada momento concreto da ação do sujeito sentidos subjetivos produzidos em outros contextos e em outros espaços de sua história pessoal, os quais coloca o sujeito e sua vida afetiva em um lugar privilegiado para a compreensão da aprendizagem.

A não-produção de sentido no processo de aprender conduz a uma aprendizagem formal, descritiva, rotineira, memorística, que não implica o sujeito que aprende. As dificuldades de aprendizagem deixam assim de ser vistas como resultado de problemas intelectuais ou orgânicos e passam a ser consideradas expressão de processos subjetivos de natureza social (2003, p. 81).

A consideração da aprendizagem escolar como uma função do sujeito psicológico, exercida a partir das suas configuraçôes subjetivas (formadas nas relaçôes sociais, no percurso de sua história de vida) e das características da situação social em que está inserido, apresenta mais uma vez formas de compreender a aprendizagem escolar que denotam sua complexidade e diversidade.

Torna-se importante que uma representação da aprendizagem escolar na sua diversidade e complexidade tome conta das instituiçóes educativas. A possibilidade de teorias únicas e integradoras da aprendizagem está distante, e a ilusão de poder encontrar facilmente estratégias de ação a partir delas não faz mais do que paralisar os esforços criativos de cientistas e educadores para compreenderem a diversidade real com que se apresenta a aprendizagem na escola.

\section{TRABALHO PEDAGÓGICO E CONCEPÇÕES SOBRE A APRENDIZAGEM}

Que forma assume o trabalho pedagógico tendo em vista concepções do que sejam e de como se processam o aprender e o ensinar? Com certeza, o trabalho que realiza o professor na sala de aula está marcado e integrado por todas as suas concepções, entre elas e bastante particularmente, aquela que diz respeito à aprendizagem e como ela se processa, pois, mesmo que seja de forma inconsciente, elas subsidiam as suas propostas e seu estilo de ensinar.

Alguns trabalhos recentes, baseados em uma abordagem histórico-cultural (BRITO, 2005; PINHEIRO, 2004; CAVALCANTE, 2004; SILVA, 2004, entre outros) examinaram concepçôes de professores tanto sobre aprendizagem e desenvolvimento, como daquilo que entendem ser o seu papel pedagógico. Nesses trabalhos, pôde-se perceber que as bases dos professores, no enfrentamento da sala de aula, repousam muito claramente em determinadas teorias que subsidiam suas concepções. 
Para a reflexão aqui pretendida, foi construído um pequeno inventário, com os objetivos de captar concepções de estudantes e professores sobre o aprender e o ensinar e de ilustrar as formas de sua sustentação em relação às teorias discutidas anteriormente. Não se objetivou uma investigação nos moldes de uma pesquisa empírica, mas apenas trazer uma ilustração do movimento das formulações e suas interligações, dando força às argumentações que sustentam este artigo.

O inventário foi aplicado no início do primeiro semestre de 2006 aos estudantes de graduação, cursos de licenciatura - formação docente, em que duas das autoras exerciam a função docente em disciplinas pedagógicas (psicologia escolar e educacional). Foi possível, assim, reunir as informaçôes de 43 estudantes que compunham duas turmas, uma procedente de uma universidade pública e outra de uma instituição privada, ambas do Distrito Federal. Em outro momento, na realização de palestra de uma das autoras em uma escola pública estadual de ensino fundamental - $1^{\text {a }}$ à $8^{a}$ série - da cidade de São Paulo, foi possível recolher informaçóes de 10 professores, aplicando-se o mesmo instrumento.

Para compor o inventário, optou-se por questões abertas de um questionário em que se pedia aos participantes que identificassem como compreendiam a aprendizagem, as condiçôes necessárias para aprender e para ensinar, os saberes necessários para ensinar, as açôes mais adequadas para esse propósito e de que forma entendiam as relações entre ensinar e aprender. Com esse conjunto de perguntas foi possível captar informações que permitiram compor um quadro de concepções com base no qual foi feito um exercício interpretativo. Tendo em vista as demonstrações pretendidas, adotou-se um modelo de apresentação menos estruturado e mais abrangente, com o objetivo de mostrar interligações entre as formulações e de indicar ancoragem das concepções que pareciam emergir. Na composição do quadro que serviu de apoio para a interpretação, constatouse que, apesar de os informantes serem de dois grupos diferentes - professores atuantes no ensino fundamental e alunos em cursos de graduação -, eles não apresentaram respostas que permitissem dar um tratamento diferenciado na interpretação. Talvez pelo fato de os estudantes estarem em situação de formação docente, seu pensamento estivesse organizando-se na perspectiva de uma atuação futura, o que os fez responder às questôes já assumindo a futura posição de professor. No entanto, qualquer conclusão a esse respeito ou explicação para as coincidências nas formulações dos professores e alunos e, em consequiência, das concepções que emergiram e da sua ancoragem, só seria possível se novos instrumentos fossem acrescentados na busca de novas informações. Mas isso fugia ao que se pretendia.

Com essas escolhas assumidas, foram realizadas as análises construtivo-interpretativas (GONZÁLEZ REY, 1997), nas quais se constatou, claramente, a tendência dos informantes de ver a aprendizagem como algo que se processa internamente a partir de algo exterior com o que se confronta o sujeito que aprende. As palavras mais freqüentes que apareceram, tanto na resposta dos alunos como dos professores, ao tentarem definir o que compreendiam por aprendizagem, foram: aquisição, assimilação, apropriação, absorção, incorporação, obtenção, captação, internalização. Ainda, verificou-se a idéia de que a aprendizagem guarda relação com memória, aparecendo palavras como evocação, 
armazenamento, retenção e reprodução. Em acréscimo, apareceu a tendência de agregar um valor utilitário ao processo de aprendizagem, pois a ocorrência de aprendizagem foi fortemente associada à questão da aplicabilidade, de aproveitamento no futuro, de utilidade ou de necessidade de ser colocada em prática. Ilustram essas tendências algumas frases a seguir reproduzidas:

- Aprendizagem é o ato de compreender e pôr em prática os elementos transmitidos pelo meio sociocultural, tendo este ato sido causado por algum estímulo.

- É o ato de incorporar um conteúdo/atitude à estrutura cognitiva pessoal, podendo utilizá-la posteriormente.

- É um processo contínuo de obtenção de conhecimento e onde se consegue aplicar esse conhecimento na prática.

- Absorver aquilo que é ensinado sem esquecer. Podendo utilizar o conhecimento sempre que necessário.

- Aprendizagem é armazenar conhecimento e aplicá-lo.

Não é difícil perceber que essas falas mostram concepçōes que podem ser inseridas nos dois grupos de teorias propostos por Hilgard (1956), ou seja, as teorias estímuloresposta e as teorias cognitivas, o que indica que elas permanecem na base de concepções sobre aprendizagem no grupo de alunos e professores que responderam aos questionários. Chama também atenção o fato de, a despeito de serem professores e estudantes, os informantes não apresentarem qualquer indício que permita inferir que diferenciam a aprendizagem escolar de outras formas de aprendizagem e, por conseguinte, que remetam à idéia da complexidade que constitui a aprendizagem escolar.

Encontra-se nas respostas dos participantes a idéia de que se aprende sempre, sobre tudo e de várias formas. Ao especificarem o que é aprendido, além de conceitos, conteúdos, do conhecimento acumulado, há o entendimento de que aprendemos sobre o mundo e sobre as pessoas, assim como também atitudes, habilidades, sobre como agir e conviver. Com muita frequiência aparece que aprendemos aquilo em que temos interesse, aquilo que se quer ou se deseja ou aquilo que a atenção seleciona, mas principalmente aquilo de que se tem necessidade ou que é preciso, tendo em vista uma condição de vida. As afirmações a seguir expressam algumas dessas idéias:

- Acho que as pessoas aprendem os conteúdos que lhes são mais interessantes ou de aplicação prática no cotidiano.

- As pessoas aprendem aquilo que lhes transmite curiosidade, às vezes, tudo parte da necessidade da pessoa, como em conseguir um emprego melhor no qual lhe é exigido um conhecimento que ele ainda não tem, mas que pode adquirir.

No entendimento sobre como as pessoas aprendem, os informantes destacam quatro aspectos, ou seja: 
1) Aprende-se por meio dos recursos ou espaços pelos quais a informação fica disponível ou acessível: pelos livros, pelas disciplinas, pelos professores, pela família, por meios tecnológicos, nas escolas, nas instituições, na rua.

2) Aprende-se nas situações contextuais: pelas conversas, pelas relações sociais, pelos exemplos, por meio de uma situação problema, pela busca autônoma, pelas trocas, pelo contato, no cotidiano.

3) Aprende-se agindo: pela experiência, pela imitação, pela observação, lendo, ouvindo (pelos órgãos do sentido), perguntando, exercitando, vivenciando, atuando, interagindo.

4) Aprende-se por meio de processos mentais, ou seja pela: memorização, evocação, compreensão, captação, deduçôes, comparações, analogias, raciocínio e pelo pensamento.

Essas informações apareceram em afirmações amplas incluindo vários aspectos, como as ilustradas a seguir:

- Acredito que as pessoas aprendem através da observação, do executar do vivenciar, das trocas.

- Através do pensamento, da compreensão, do raciocínio, do interesse e do conhecimento adquirido.

- Através de comparações, deduções e analogias com outras situaçóes do cotidiano.

- Acredito que as pessoas aprendem dentro das relaçóes sociais, nas diferentes situações em que se encontram: na rua, na escola, no dia-a-dia.

- O aprendizado se dá pelo contato que pode ocorrer por um dos sentidos (tato, visual, auditivo). Aprende-se lendo, ouvindo, vivenciando.

- Por imitação, através do exemplo e em etapas graduais.

- Aprendem pela memorização de informaçôes consideradas pertinentes.

- Ocorre uma captação da informação, depois a memorização e logo após a capacidade de evocar o que foi abstraído.

A partir dessas informaçōes, pode-se admitir que existe alguma tendência para considerar que o aprender é possibilitado nas diferentes situações de vida e que a aprendizagem acontece nas relações sociais, em um processo de interação. Não há, todavia, nas falas dos informantes, qualquer indicativo de que isso seja considerado como fundante do processo de aprendizagem. Fica também evidenciado um pensamento centrado em aspectos sensoriais (tato, visão, audição), cognitivos (memorização, evocação, imitação etc.) e na experiência prática. Essa maneira de pensar encontra respaldo e se conecta com concepções mecanicistas e não refletem a complexidade da aprendizagem escolar, o que será confirmado também em análises subseqüentes.

De uma forma especular ao aprender, o ensinar, coerentemente, adquire o formato de algo externo a ser repassado ao aluno, ou seja, aparece a idéia de transmissão do conhecimento, de uma influência a ser exercida, o que se expressa em afirmaçôes como: 
- É o conjunto de técnicas abordadas e aplicadas para transmitir o conhecimento de determinada ou determinadas disciplinas.

- O detentor do que será ensinado, através de algum método, passará algum ensinamento novo para um terceiro.

Para elegerem as condições necessárias ao aprender e ao ensinar, os informantes indicam tanto aspectos relativos a condiçôes pessoais de alunos e de professores como aspectos instrumentais abrangendo a estrutura física e os recursos didático-pedagógicos da escola. $\mathrm{O}$ interesse, a curiosidade, a concentração e a motivação para aprender, assim como a boa vontade, a disposição, a motivação e a dedicação para ensinar ficam muito evidenciados nas respostas, quando são indicadas as condições pessoais. São afirmativas que podem ser assim ilustradas:

- Deve existir interesse da pessoa. A motivação e disposição devem estar presentes. Deve existir um objetivo.

- Que se tenha vontade de aprender, curiosidade, repasse de informação e, ainda, importância ou significado para o sujeito da aprendizagem.

Para ensinar, ainda foram ressaltados aspectos da formação docente, como saber os conteúdos, ter conhecimento pedagógico e didático, gostar da profissão e ter dedicação, conforme aparece nas frases que informam condições necessárias para ensinar. Não foram esquecidas, também, as questôes salariais:

- Sentir-se estimulado, animado; ter boa formação e formação continuada; amplo conhecimento. Conhecer o conteúdo, preparar a aula.

- Estar preparado, ser experiente, ter conhecimento didático e ter equilíbrio emocional.

- Bom salário, local de trabalho adequado, material pedagógico diversificado.

Todos esses aspectos são, de fato, importantes partícipes da ação do professor, mas percebe-se entre os informantes uma tendência à maior valorização da formação técnica do professor, em detrimento dos aspectos pautados no reconhecimento da singularidade do aluno e do compromisso com a promoção de sua aprendizagem e de seu desenvolvimento.

A priorização da formação técnica do professor é também evidenciada em formulações sobre os saberes necessários para a ação docente. $\mathrm{O}$ carro chefe das respostas recai sobre o domínio dos conteúdos, aparecendo, em seguida, o conhecimento sobre didática. Incluem-se, aí, alguns recursos pessoais, como ser dinâmico, saber motivar ou despertar o interesse do aluno. São exemplos dessas afirmaçôes:

- Tem que ter domínio do conteúdo, ter didática e ser dinâmico.

- É necessário ter o domínio do assunto, desenvoltura, boa comunicação. 
- É necessário ser dinâmico para prender a atenção dos alunos e saber todo o conteúdo da matéria ministrada.

- Apresentar o conteúdo com clareza e utilizar recursos didáticos.

- O professor precisa ter didática e um vasto conhecimento sobre o que ele ministra. Didática porque não adianta o professor ter muito domínio do conteúdo se não consegue passar para o aluno.

Pode-se argumentar que o fato de considerarem o conteúdo como essencial na ação docente não autoriza a afirmação de que esses informantes priorizam a formação técnica, na medida em que a atividade docente gira em torno de uma área do conhecimento que deve ser dominada. No entanto, quando se leva em conta os outros saberes que indicam como necessários, mostra-se a procedência de tal conclusão. Nessa indicação, o foco recai sobre conhecimentos relacionados a alunos, de um modo geral. As respostas declaram: saber o nível do aprendizado do aluno, seus interesses, suas necessidades e suas dificuldades, sua realidade, a forma como aprendem, incluindo as diferenças individuais. Essas e outras declaraçóes evidenciam que os informantes destacam que o processo ensino-aprendizagem é composto de três elementos: um conteúdo a ser ensinado, um professor que ensina e um aluno para o qual o conteúdo é ensinado. Pode-se supor que os conhecimentos sobre o aluno, identificados como necessários, apontariam para uma preocupação com o sujeito aprendiz na produção de sentidos na aprendizagem. Entretanto, as ênfases não permitem essa inferência, pois elas revelam que o professor considera importante saber de aluno, mas não de um aluno, aquela pessoa concreta com quem interage. Assim sendo, as referências feitas ressaltam apenas aspectos que dizem da necessidade de conhecer, genericamente, sobre diferenças individuais, sobre a forma como se aprende, sobre necessidades e interesses de aprendizes. Pode-se inferir ser esse um conhecimento sobre um aluno coletivizado, abstraído, e não uma pessoa real, subjetivamente envolvida no processo de aprender. São saberes instrumentais sobre os alunos, movidos mais pela necessidade de dar uma direção ao processo de transmitir conhecimentos do que de uma preocupação com a produção de sentidos ou com as significações que cada aluno faz, no momento da aprendizagem.

Ocorrem também expressões que consideram o equilíbrio emocional ou o bem-estar psicológico como elementos importantes, tanto para ensinar como para aprender, e também são feitas referências às capacidades cognitivas, intelectuais e às contribuiçôes relevantes da família, mesmo que isso apareça de forma bastante esparsa. Todas essas expressões mostram que existe uma tendência a afirmar que algo já deve estar constituído a priori na pessoa para que o processo de aprender seja possível ou bem sucedido, algo que, portanto, não é visto como decorrente das relações sociais.

Chama a atenção o apelo aos aspectos do ambiente e da estrutura física, que aparece de forma muito freqüente, evidenciando a importância que isso tem para os informantes, quando pensam nas condiçōes para o aprender e o ensinar. Isso fica demonstrado em afirmações como:

- Um ambiente educacional agradável com os equipamentos necessários. 
- Concentração, ambiente limpo e organizado, confortável.

- É necessária uma estrutura física boa, com iluminação adequada, boa ventilação e um quadro.

- As condiçốes físicas e as condiçôes psicológicas creio que sejam determinantes como condições necessárias para a aprendizagem.

È claro que recursos materiais são bem-vindos no processo ensino-aprendizagem, mas a forte ênfase que receberam fazem crer que eles constituem uma condição básica do processo para os informantes, que justificariam a não-consecução dos objetivos escolares.

Pôde-se constatar declarações que anunciam preocupaçōes com o aluno individual, ou seja, é vista uma necessidade de conhecer o aluno, de acreditar nele e de estabelecer com ele uma relação dialógica:

- É preciso conhecer o aluno; acreditar nele.

- Deve haver abertura para o diálogo, flexibilidade; uma relação dialógica onde ambos, professor e alunos, aprendam e ensinem.

No entanto, a referência ao diálogo pode significar apenas o consentimento para que o aluno expresse sua opinião, e não ouvi-lo, verdadeiramente. Isso se afasta do que González Rey (1995) propõe como comunicação: um processo em que professor e aluno implicam-se como sujeitos e que promove, a cada momento, novos motivos na interação, ampliando-a e conferindo-lhe valor para a aprendizagem e o desenvolvimento do estudante. Essa possibilidade interpretativa fica um tanto mais forte quando se verificam falas como a de um futuro docente, declarando que, para que o processo ensino-aprendizagem aconteça, "no mínimo é necessário um educador que passe (transmita) conhecimentos com autonomia e dedicação e que haja discípulos que queiram ser moldados".

Vê-se que professores e estudantes em processo de formação docente filiam-se a visões teóricas com forte cunho naturalista e que procuram explicar a aprendizagem de um modo reducionista.

\section{CONCLUSÃO}

Ainda que o apogeu do ciclo das teorias da aprendizagem já tenha passado, pode-se afirmar que a sua presença é conspícua. Isso denota a forte articulação que há entre psicologia e educação, ponto principal do exame aqui pretendido. Entretanto, mais do que isso, ela inocula uma preocupação. Do início e apogeu desse ciclo de produção teórica na psicologia até os dias de hoje, o mundo passou por grandes mudanças. A despeito delas, a escola continua arraigada a modos de compreensão do aprender e, especularmente, do ensinar, que negam a diversidade das formas de aprender, seja pela singularidade da pessoa que aprende, seja pela peculiaridade do contexto social em que a aprendizagem ocorre. O entendimento dessa aliança entre psicologia e educação parece justificar, assim, o esforço de futuros trabalhos. 
Conforme foi visto, não ocorreu qualquer indício de que haja entre professores e estudantes em processo de formação docente uma idéia da possibilidade de se afirmar a especificidade da aprendizagem escolar. Segue-se concebendo-a como uma aprendizagem qualquer. Embora, simultaneamente ao ciclo das teorias da aprendizagem, a psicologia tenha oferecido contribuiçôes teóricas que permitam afirmar a diversidade das formas de aprender, conforme foi apontado, ao que tudo indica, a educação escolar não as incorporou. Que hegemonia é essa? O que a escola vem, historicamente, oferecendo à psicologia? E, em contrapartida, o que vem a psicologia, historicamente, oferecendo à escola? É verdade que o inventário aqui apresentado não contempla os cânones estatísticos que permitam uma generalização. Entretanto, talvez isso não seja necessário, dada a abundância de estudos que qualquer iniciante reconhece existir na área e que apontam na mesma direção do que foi aqui examinado. É muito provável que não haja deslize em se afirmar que o trabalho pedagógico ainda é pensado e realizado com base em concepções fortemente repousadas em sistemas teóricos que induzem ao mecanicismo e ao naturalismo, apesar da existência, na própria psicologia, de outras teorizaçôes que permitiriam uma compreensão diferente. Isso explica por que os processos de ensino-aprendizagem são propostos em uma perspectiva de assimilação de uma realidade exterior, o que exclui o sujeito e seu processo de subjetivação da aprendizagem. Qual é o poder das premissas adotadas pelos principais teóricos da aprendizagem e que são acatadas, quase em uníssono, pela escola? Essa é uma outra questão que parece merecer exame.

Será que é possível falar em conclusão?

\section{Notas}

1. Diz o autor: "Mesmo ampliando enormemente a esfera de ação dos estímulos eliciadores, o processo de condicionamento não abrange todo o comportamento do organismo controlado por esses estímulos. De acordo com a fórmula da substituição de estímulos, precisamos eliciar uma resposta antes de condicioná-la. Destarte, todos os reflexos condicionados baseiam-se em reflexos incondicionados. Mas já vimos que as respostas reflexas são apenas uma parte do comportamento total do organismo. O condicionamento proporciona novos estímulos controladores, mas não pode acrescentar novas respostas. Assim, ao usar o princípio, não estamos presos a uma 'teoria dos reflexos condicionados' para todo o comportamento" (SKINNER, 1967, p. 39).

2. Diz o autor: "Através do condicionamento operante, o meio ambiente modela o repertório básico com o qual mantemos o equilíbrio, andamos, praticamos esporte, manejamos instrumentos e ferramentas, falamos, escrevemos, velejamos um barco, dirigimos um automóvel ou pilotamos um avião" (SKINNER, 1967, p. 44). 


\section{Referências}

ABUlJÁnOVA, A. K. El sujeto de la actividad psíquica. Trad.: M. Merino. México: Roca, $1973 / 1985$.

ARIÈS, Philippe. História social da criança e da família. Trad.: Dora Flaksman. Rio de Janeiro: LTC, 1981.

BOTO, Carlota. O desencantamento da criança: entre a Renascença e o Século das Luzes. In: FREITAS, Marcos Cezar de; KUHLMANN JÚNIOR, Moysés (Orgs.). Os intelectuais na história da infância. São Paulo: Cortez, 2002. p. 11-60.

BOZHOVITCH, Lidia Iliinitchna. La personalidad y su formación en la edad infantil. Trad.: C. T. Muñiz. La Habana: Pueblo y Educación, 1982/1985.

BRITO, Ildamar Farias. Desenvolvimento infantil: concepções de professores e suas implicações na manifestação do preconceito. Dissertação de Mestrado em Educação, Universidade de Brasília, 2005.

CAVALCANTE, Andréa Vasconcelos. O preconceito da deficiência no processo de inclusão escolar. Dissertação de Mestrado em Educação, Universidade de Brasília, 2004.

CUNHA, Maria Isabel. O bom professor e sua prática. Campinas: Papirus, 1999.

DAVIDOV, Vasilii Vasilievitch; MARKOVA, Aelita Kapitonovna. La concepción de la actividad de estudio en los escolares. In: DAVIDOV, Vasilii Vasilievitch; SHUARE, Martha (Orgs.). La psicologia evolutiva en la URSS. Moscow: Progreso, 1987.

GONZÁLEZ REY, Fernando Luís. Comunicación, personalidad y desarrollo, La Habana: Pueblo y Educación, 1995.

GONZÁLEZ REY, Fernando Luís. Epistemología cualitativa y subjetividad. La Habana: Pueblo y Educación, 1997

GONZÁLEZ REY, Fernando Luís. Sujeto y Subjetividad: una aproximación histórico-cultural. México: Thomson, 2002

GONZÁLEZ REY, Fernando Luís. El aprendizaje en el enfoque histórico-cultural: sentido y aprendizaje. In: TIBALLI, Elianda Figueiredo Arantes; CHAVES, Sandramara Matias. (Orgs.). Concepçôes e práticas em formação de professores. diferentes olhares. Rio de Janeiro: DP\&A, 2003. p. 75-86.

HILGARD, Ernest Ropiequet. Teorias da aprendizagem. Trad.: N. P. Mejias, H. A. Guedes e C. Rameh. São Paulo: Herder, 1956/1966.

ITELSON, Lev Borisovitch. La actividad docente. Sus orígenes, estructura e condiciones. In: ILIASOV, Islam Imranovitch; LIAUDIS, Valentina Yakovlevna (Orgs.). Antologia de la psicologia pedagógica e de las edades. Trad.: C. R. Garcia. La Habana: Pueblo y Educación, 1986. p. 94-99.

KELLER, Fred Simmons. Aprendizagem: teoria do reforço. Trad.: R. Azzi, L. Zimmerman e L. O. S. Queiroz. São Paulo: Herder, 1970.

MARKOVA, Aelita Kapitonovna; ABRAMOVA, Galina Sergueievna. La actividad docente como objeto de investigación psicológica. In: ILIASOV, Islam Imranovitch; LIAUDIS, Valentina Yakovlevna (Orgs.). Antologia de la psicologia pedagógica e de las edades. Trad.: C. R. Garcia. La Habana: Pueblo y Educación, 1986. p. 104-109. 
PINHEIRO, Paixão Marilete Alves. Sucesso escolar: uma possibilidade na relação professor x aluno, Brasília, UnB, Dissertação de Mestrado em Educação, 2004

POSTMAN, Neil. O desaparecimento da infância. Rio de Janeiro: Graphia Editorial, 1999. POZO, Juan Ignacio. Aprendices y maestros: la nueva cultura del aprendizaje. Madrid: Alianza, 2000.

PRANGUISHVILI, Aleksandr Severianovitch. El aprendizaje y la disposición. In: ILIASOV, Islam Imranovitch; LIAUDIS, Valentina Yakovlevna (Orgs.). Antologia de la psicologia pedagógica e de las edades. Trad.: C. R. Garcia. La Habana: Pueblo y Educación, 1986. p. 104-109.

SILVA, Raimundo Nonato. Concepçôes, crenças e valores de alunos e professores: analisando situações de conflito na sala de aula, Brasília, UnB, Dissertação de Mestrado em Educação, 2004.

SKINNER, Burrhus Frederic. The behavior of organisms. New York: Appleton-Century-Crofts, 1938.

SKINNER, Burrhus Frederic. Ciência e comportamento humano. Trad.: João Cláudio Todorov e Rodolpho Azzi. Brasília: Edunb, 1967.

SKINNER, Burrhus Frederic. Cumulative record: a selection of papers. New York: AppletonCentury-Crofts, 1972.

TIJOMIROV, Oleg Konstantinovich. Psijaloguia michlienia (em russo). Moscou: Universitária, 1984.

TOFFLER, Alvin. A terceira onda. Trad.: João Távora. Rio de Janeiro: Record, 1980.

TUNES, Elizabeth. O estudo do desenvolvimento. In: CORRÊA FILHO, Laurista; CORREA, Maria Elena Girade; FRANÇA, Paulo Sérgio (Orgs.). Novos olhares sobre a gestação e a criança até três anos: saúde, perinatal, educação e desenvolvimento do bebê. Brasília: L.G.E., 2002. p. 135-150. TUNES, Elizabeth; BARTHOLO JÚNIOR, Roberto dos Santos. Da constituição da consciência a uma psicologia ética: alteridade e zona de desenvolvimento proximal. In: SIMÃO, Lívia Mathias; MITJÁNS MARTÍNEZ, Albertina (Orgs.). O outro no desenvolvimento humano: diálogo para a pesquisa e a prática profissional em psicologia. São Paulo: Pioneira Thomson Learning, 2004. p. 41-60.

VIGOTSKI, Liev Semionovich. Teoria e método em psicologia. Trad.: Cláudia Berliner. São Paulo: Martins Fontes, 1996.

VIGOTSKI, Liev Semionovich. Psicologia pedagógica. Porto Alegre: Artmed, 2003.

VIGOTSKI, Liev Semionovich. Fundamentos de defectologia. Madrid: Visor Distribuidora, 1997. VIGOTSKI, Liev Semionovich. Pensamiento y lenguaje. Trad.: M. M. Rodger. La Habana: Revolucionaria, 1934/1968. 


\title{
A critical argument on classical learning theories and on the way they are expressed in educational practices
}

\begin{abstract}
In this paper, we aim at comprehending the ways in which psychology and education interpenetrate each other. The reflection is based on learning theories which serve as the scenario of a cycle of theoretical production in psychology, in search of the main line of thinking of concrete ways in which teachers and students carry out their practices in education. With psychology's historical-cultural perspective as a basis, a critical examination of the most known learning theories is made while trying to demonstrate their convergences and their limits in treating the diversity of human learning types, especially the ones that take place inside the school institution.
\end{abstract}

Keywords: Psychology. Education. Learning theories.

\section{Une critique aux théories classiques d'apprentissage et leur expression dans le champs éducatif}

\section{Résumé}

Dans ce travail, nous cherchons à comprendre les façons par lesquelles la psychologie et l'éducation sinterpénètrent l'une avec l'autre. La réflection est basée sur les théories d'apprentissage qui servent de cénario pour un cycle de production théorique en psychologie, tout en cherchant les fils conducteurs des manières par lesquelles les maîtres et les étudiants affirment leurs pratiques en éducation. Utilisant la perspective psychologique historique-culturelle comme fondement, un examen critique des théories d'apprentissage plus connues est fait tout en essayant de démontrer leurs convergences et leurs limites en traitant la diversité des formes d'apprentissage humain, spécialement celles qui prennent place au sein de l'institution école.

Mots clefs : Psychologie. Education. Théories d'apprentissage.

\section{Uma crítica às teorias clássicas da aprendizagem e à sua expressão no campo educativo}

Resumen

En este trabajo se intenta compreender algunas de las formas de interpenetración entre Psicología y Educación. El escenario para la reflexión lo constituyen las teorías de aprendizaje como un ciclo de producción teórica de la Psicología, siendo el hilo conductor la buisqueda de las formas concretas en que profesores y estudiantes afirman sus prácticas en el campo de la Educación. A partir de la Teoría históricocultural de la Psicología se hace un análisis crítico de las teorías de aprendizaje más conocidas, procurándose demostrar sus puntos de convergencia y también sus limites para explicar la diversidad de formas del aprendizaje humano, especialmente las que tienen lugar en la institución escolar.

Palabras-clave: Psicología. Educación. Teorías del aprendizaje.

Recebida I ${ }^{\text {a }}$ versão em: 05.06.2006

Aceita $2^{\text {a }}$ versão em: 18.09.2006 